
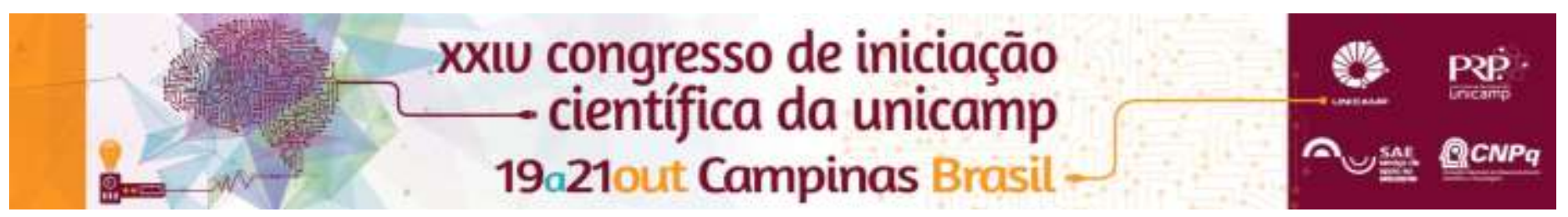

\title{
TRAPP Catadores: Territorialidades
}

\author{
Laura Silva Barboza*, Maria Júlia dos Santos Peinado*, Mikaelle Stefany Silva Aguiar*, Paulo Eduardo de Freitas \\ Saroa*, Antônio Hélio Rodrigues de Souza, Tainá A. Vedovello Bimbati, Emília Wanda Rutkowski
}

\section{Resumo}

O objetivo do trabalho foi analisar o comprometimento ambiental na cidade universitária Zeferino Vaz por meio da separação de recicláveis. Para reconhecer a realidade de Campinas visitou-se cooperativas de catadores de materiais recicláveis e fez-se gravimetria de resíduos de salas de aulas de três faculdades. Os resultados mostraram que resíduos orgânicos, recicláveis e rejeitos são misturados, apontando para a falta de comprometimento ambiental atenuada pela ausência de lixeiras específicas.

\section{Palavras-chave:}

Território, Resíduos Sólidos, Comprometimento Ambiental.

\section{Introdução}

O conceito de territorialidade envolve entendermos o nosso papel dentro de um território e a forma como nos relacionamos com o meio e as pessoas (Santos, 2007). É o vínculo da pessoa com o lugar, com tudo que ele representa. Para tal é essencial que nosso direito ao saneamento básico seja garantido, conforme o Estatuto das Cidades (Lei 10.257 de 2001). De acordo com a Política Nacional de Saneamento Básico (Lei 11.445 de 2007) o saneamento inclui os serviços de tratamento e manejo de resíduos sólidos, ou seja, atividades de coleta, transporte, tratamento e destino final adequado dos resíduos e deve contar com a participação de catadores de materiais recicláveis e reutilizáveis (Lei 12.305 de 2010 - PNRS). Um campus universitário é um grande gerador de resíduos sólidos com uma população sensibilizada para as questões ambientais. Este trabalho objetivou analisar o comprometimento ambiental da comunidade da cidade universitária Zeferino Vaz em relação a segregação adequada dos recicláveis.

\section{Resultados e Discussão}

Com o objetivo de reconhecer as relações sobre o comprometimento ambiental no território que se vive, este trabalho foi desenvolvido em etapas. A primeira foi a construção do Mapa "Territorialidade" para permitir a identificação da territorialidade. O mapa representou 0 trajeto Casa - Escola - Universidade usando ícones do Green Map referentes a características ambientais, sociais, culturais e políticos, como a Prefeitura, praças, coleta seletiva.

$\mathrm{Na}$ segunda etapa foi estudado como a gestão de resíduos sólidos deveria acontecer pelas políticas públicas nacionais e estaduais, como o Plano Diretor do município de Campinas, a Lei 11.445 de 2007 (PNSB) e Lei 12.305 de 2010 (PNRS).

A terceira etapa buscou reconhecer a realidade vivida pelo município de Campinas por meio de visitas às cooperativas de catadores de materiais recicláveis e reutilizáveis. Elas possuem diferenças quanto a infraestrutura, equipamentos, condições de trabalho e quantidade de material coletado, triado e vendido. Possuem um papel essencial no processo de reciclagem dos resíduos sólidos municipais e na qualidade de vida da sociedade.
A quarta etapa foi analisar a realidade da Universidade em relação à gestão dos resíduos sólidos a partir de uma gravimetria para identificar os tipos de resíduos produzidos dentro das salas de aula da Faculdade de Engenharia Civil, Arquitetura e Urbanismo (FEC), Faculdade de Engenharia Química (FEQ) e Faculdade de Ciências Médicas (FCM). No diagnóstico foi constatado que havia apenas uma lixeira nas salas de aula misturando todos os tipos de resíduos, fazendo com que os recicláveis sejam levados para contêineres de não recicláveis. Os resultados são mostrados a seguir.

Tabela 1. Composição gravimétrica dos resíduos sólidos (\%)

\begin{tabular}{|l|c|c|c|}
\cline { 2 - 4 } \multicolumn{1}{c|}{} & FCM & FEQ & FEC \\
\hline Recicláveis & $39,6 \%$ & $22,7 \%$ & $74,2 \%$ \\
\hline Orgânicos & $55,4 \%$ & $76,0 \%$ & $25,3 \%$ \\
\hline Rejeitos & $5,0 \%$ & $1,3 \%$ & $0,5 \%$ \\
\hline
\end{tabular}

Apenas aumentar a quantidade não resolveria o problema. A solução seria colocar lixeiras para recicláveis, orgânicos e rejeitos em todas as salas de aula com orientações sobre o tipo de resíduo que cada lixeira pode receber. Além disso, deve haver uma sensibilização com os estudantes e encarregados pela limpeza das salas de aula, para que ao fazerem a coleta, não misturem os resíduos.

\section{Conclusões}

Concluímos que a segregação de recicláveis não ocorre de forma eficiente nas unidades observadas, assim como faltam lixeiras específicas para cada tipo de resíduo nas salas de aula, atenuando a falta de comprometimento ambiental. A maneira como nos relacionamos com o território influencia na gestão dos resíduos sólidos, por isso é necessário um trabalho de envolvimento com toda a comunidade para garantir o comprometimento ambiental.

\section{À FAEPEX.}

\section{Agradecimentos}

\footnotetext{
1 Santos, Milton. O Espaço do Cidadão. 7. ed. - São Paulo: Editora da Universidade de São Paulo, 2007. 176 p.; 14 x $21 \mathrm{~cm}$.

2 BRASIL. Lei Federal 11.445 de 2007. Política Nacional de Saneamento Básico

${ }^{3}$ BRASIL. Lei Federal 12.305 de 2010. Política Nacional de Resíduos Sólidos

${ }^{4}$ BRASIL. Lei Federal 10.257 de 2001. Estatuto das Cidades
} 